\title{
22
}

\section{The use of process modelling in benchmarking}

\author{
S J Childe \& P A Smart \\ School of Computing, University of Plymouth, \\ Plymouth PL4 8AA, United Kingdom
}

The increasing interest in benchmarking as a tool for achieving radical improvements in a business' competitive performance has encouraged many companies to attempt a comparison of their performance to that of others. This has been attempted in two main ways. Companies who compare their performance to that of their competitors restrict their potential operating improvements to a position of equality with the competitor, who may by then have moved on. Those companies attempting to look into other industries to gain real originality may fail if they do not focus on activities which are directly comparable. This paper looks at the need to identify the correct activities to study and proposes a modelling technique which can help the company to establish a baseline for comparison.

\section{WHAT IS BENCHMARKING?}

The term "benchmarking" has become the vogue term in the management arena in the nineties. One may suppose its origin lies in other professions such as carpenters or drapers who may have made marks upon their benches to allow standard measurements to be taken. The term has also been defined [Chambers 1988] with reference to the discipline of surveying:

"A surveyors mark .... indicating a point of reference .... anything taken or used as a point of reference or comparison, a standard, criterion etc"

A useful definition of benchmarking is as the development and use of reference points or standards against which business performance can be judged.

Bob Camp [1989] describes Benchmarking as "the search for those best practices that will lead to superior performance for a company". His text presents a structured approach for searching for those industry best practices and implementing them into a business environment. A number of philosophical steps which are fundamental to the success of benchmarking are identified:

* Know your operation

* Know the industry leaders or competitors 
* Incorporate the best

* Gain superiority

The ability to gain superiority is dependent upon a detailed understanding of the company's own operations and those of others and the ability to incorporate these to develop performance improvements. It is the authors' opinion that many companies which attempt benchmarking go ahead without the detailed knowledge of their own business which is vital to allow the appreciation and assimilation of the best practice exemplified in other companies.

The process of searching for industry best practices should be seen as a learning activity. Companies learn how they operate, they try to learn how their competitors operate, and aim to learn how industry leaders operate, so that they can apply the knowledge gained to their own businesses. Paradoxically, while benchmarking tends to focus upon learning about others, its success may depend upon learning about the company's own processes to set the agenda for the study and to allow the findings to be used.

External comparison depends upon being able to identify the leaders whose practice is the best. This knowledge may not be available within the company and assistance from external knowledge sources may be required. These sources might be consultants, academics or institutions such as benchmarking groups. As the company performs successive benchmarking exercises, this knowledge base can be expected to increase.

"Best practice" may be hard to find. It would be impossible for a company to conduct an exhaustive search of all the potential best practices across all industry sectors. This means that it is likely that a company would not identify the overall best exemplar. The company must conduct their search for best practice given the limitations imposed on them by their available knowledge base, that is to say, they may only search for those industry best practices which they feel to be most appropriate given their knowledge of the industrial sector. This base should grow and provide more pertinent pointers to the industry best as the number of iterations of the benchmarking process increases.

If companies are to emulate the practices of other firms it would appear that the best possible result would be to match their performance, since it appears to be impossible to surpass the standard upon which the exercise is based. However, this would be to overlook the benefits from formulating a hybrid "better" process comprising the best ideas from the studies conducted. To excel in this area the company must use the knowledge gained as a potential source for creativity. Without this sort of innovative process a company can never aspire to be a leader itself. Benchmarking must not be seen as a strategy to imitate other companies but as a mission to use the experience of others as a source for novel ideas. This approach is discussed by Smith et al [1992].

\section{IDENTIFICATION OF ACTIVITIES FOR BENCHMARKING}

The concepts of best practice and benchmarking sometimes appear to trivialise the problem by addressing a level of performance which can be described as "best" or as "best in class". This overlooks the simple question of how to measure performance. The company which performs a particular activity in the best way to suit its own particular business strategies - possibly quite well known as the most successful company in the business - may not address the same aims as the company who wishes to learn from them. 
Simple performance measures can be used to illustrate this point. Manufacturing companies often base their strategies upon a particular balance between the measures of cost, quality, functionality, delivery lead time and delivery reliability etc. If a company has a strategy of operating a particular activity at the lowest cost, it may make compromises to the service it offers to its customers, for example. A company in the upper end of the market might compete primarily upon the basis of service quality. For these two companies, the best way of achieving the activity may mean two different things. They may be incompatible for benchmarking purposes.

The activities which are to be compared must therefore be identified not only on the similarity of the task but also on the basis of the competitive business objectives which govern the task. If they do not agree, there may be scope for learning from an alternative approach, as long as the differences are understood.

Similarly, the business environment must be considered when selecting a benchmarking partner. For example, if a company was benchmarking its procurement activities, it would not necessarily be wise for a company in the business of one of a kind production to benchmark itself against a high volume low variety producer, because the competitive requirements of one company would not be satisfied by the activities found to be good at addressing the requirements of the other. The way a company needs to manage its supply arrangements in a high volume business where "clout" is available is likely to be quite different to the arrangements which would enable the purchase of small numbers of widely different items from a wide range of suppliers. However, we may also argue that to achieve radical performance gains, looking at activities in radically different companies might be a valuable exercise. A good example of this is provided by the well known case study illustrating the benchmarking exercise between Xerox and L L Bean [Camp 1989].

Following the implementation of a planning system in the inventory control area, Xerox identified the picking operation as the greatest bottleneck.

The benchmarking effort resulted in L L Bean - an outdoor sporting goods retailer and mail order house - being used as the main benchmarking partner. Whilst the two companies would appear to be dissimilar, the processes were comparable:

"... L L Bean products may bear no resemblance to Xerox parts and supplies. To the distribution professional, however, the analogy was striking: both companies had to develop warehousing and distribution systems to handle products diverse in size, shape and weight" [Camp 1989]

If it is accepted that a similar activity with similar competitive priorities can be found in a potential benchmarking partner, one may assume that there would then be a reasonable foundation upon which to copy the superior performing company's practices. This reassurance would increase as a function of the degree of consistency in the nature of the task - the inputs and outputs agreeing - and the degree of consistency in the performance measures. Unfortunately the simple act of copying from another company may not be a simple as it seems.

It was pointed out by Juran in his address to the winners of the Malcolm Baldridge National Quality Award in 1989 
"to learn from experience requires a transfer of knowledge. Such a transfer of know-how should not be done by mimicking what the winners did. Mimicking is risky because of the differences in respective cultures. A reliable transfer of know-how requires thinking through what are the lessons learned .... it is the universals which are transferable from one culture to another."

Hayes and Pisano observe [1994] "Two companies may adopt similar strategies and production processes, but one can end up being far more successful". A strategy shift is needed to that of "learning" from the experience of others rather than copying. This shift is from imitating other companies to using them as a source for novel ideas [Smith et al 1992].

The use of benchmarking as a source for novel ideas provides the basis for the potential creation of innovative activities. Viewing benchmarking in this fashion also provides the potential to surpass the industry best. Copying implies only matching the performance of a particular activity, whereas the creation of hybrid solutions based on the industry best has the potential to itself be the best, since it creates something original and new.

Benchmarking, viewed as the basis for corporate learning, therefore requires a technique to allow:

* the identification of the key business activities;

* detailed activity definition to allow comparison with other companies;

* the characterisation of the relevant performance measures.

This should allow benchmarking to operate across industry boundaries between companies who do not compete with each other.

\section{DESCRIPTION OF BUSINESS ACTIVITIES}

In order to ensure that the benchmarking exercise compares like with like, and to ensure the performance measures and other conditions are similar, a means for describing activities and business processes is required which allows the appropriate level of detail to be drawn out, and which allows the performance criteria to be compared. This can be achieved by the use of a hierarchical method which allows activities to be decomposed into various levels of detail, whilst showing the business context which provides some information about performance requirements. Some light is shed on this problem by the research work currently being undertaken in the field of Business Process Re-engineering. Companies are beginning to explore the questions of "how can I identify processes in my business?" and "what is a business process?"

According to Davenport and Short [1990], a business process is "the logical organisation of people, materials, energy, equipment and procedures into work activities designed to produce a specified end result". Davenport and Short also state that processes have two important characteristics. Firstly, they have customers and secondly, they cross organisational boundaries and are generally independent of formal organisational structure.

Similarly, Hickman [1993] defines a business process as "a logical series of dependent activities which use the resources of the organisation to create, or result in, an observable or 
measurable outcome, such as a product or service". The authors would add that a business process must be initiated by and must provide results to a customer, who may be internal or external to the company.

A useful structure established by the CIM-OSA standards committee [1989] subdivides processes into three main areas: Manage, Operate and Support. The CIM-OSA framework regards manage processes as those which are concerned with strategy and direction setting as well as with business planning and control. Operate processes are viewed as those which are directly related to satisfying the requirements of the external customer, for example the logistics supply chain from order to delivery. Support processes typically act in support of the Manage and Operate processes. They include the financial, personnel, facilities management and Information Systems provision (IS) activities. These definitions serve as a framework which the company may use to focus its benchmarking efforts. Further focus comes from the identification of the processes within these groupings.

\section{DEFINITION OF BUSINESS PROCESSES}

In the authors' view a business process operates in a manner analogous to the operation of an industrial or chemical process in as much as it comprises "a series of continuous actions or operations ...." [Hawkins 1984] which are performed upon a commodity. It may also be regarded as a conduit along which a commodity flows. In this context, a commodity might be conceptual or material. Such commodities pass along their respective process conduits and are transformed, at different stages in their progress, as various operations are performed upon them. An activity for benchmarking can therefore be defined by the process of which it is a part.

\subsection{Manage processes}

\section{Direction Setting}

This process includes all high level strategic planning activities. It acts as an overall managing activity which takes ideas about direction based upon business and environmental information, including customer feedback, and transforms these into a set of strategies, operational goals and performance measures.

\subsection{Operate processes}

\section{Order Flow (Products)}

The Order Flow process takes the customer order and transforms it into a finished product. The commodity which flows through this process is the customer's specific product requirement. This initially takes the form of an order and is transformed into a product which embodies the customer's requirement. As the order flows in one direction, money flows in the other: thus the process ends only when the product is accepted and paid for by the customer. 
Activities within this category may include raw material purchasing, product assembly, the production of the product, obtaining orders, delivery and installation of the product, invoicing and money receipt.

\section{Service}

This process takes the customer's requirement for a service and satisfies it by providing that service. For example the requirement could be the need to keep machines operating reliably, transformed by the service into an assurance of trouble-free performance. Activities include the management of customer enquiries and the provision and management of the necessary technical support to satisfy the customer.

\subsection{Support processes}

There are a considerable number of activities which are required to support the key business processes. These relate the company to its business environment, which can be thought of as a series of markets within which the company operates. These have been identified by Fine and Hax [1984] as capital markets, labour markets, technology markets, factor markets and product markets. Each of these markets is addressed by the company through a business process.

\section{Capital markets}

The process attracts investment into the firm and provides benefits (typically shareholder dividends) thus maintaining the company's position in the capital market.

\section{Labour markets}

The process of recruiting, training, remunerating, motivating, appraising and retiring employees. By processing employees, the company maintains its human resources and its position with respect to the labour market.

\section{Technology markets}

The assessment and development of available technology, and the selection, installation, maintenance and disposal of plant and equipment.

\section{Factor markets}

The establishment and development of relationships with suppliers, supplier development and liaison, and the termination of relationships with suppliers no longer required. This process may also be concerned with the make-or-buy decision.

\section{Product markets (and the market for services)}

The company retains its competitive position in the market place by a process which maintains the awareness of its potential customers. This "marketing" activity may be seen as part of the operating process since it involves obtaining orders and providing service, and since the company's position in the product marketplace must ultimately depend on the way in which orders are satisfied. 


\section{PROCESS MODELLING}

Having identified the process which is to be considered for benchmarking, the process must be presented in a way which allows communication, understanding and analysis. Various types of process modelling tools fulfil these requirements. One of the most popular tools is $\mathrm{IDEF}_{0}$.

$\mathrm{IDEF}_{0}$ comprises:

* A set of methods that assist in understanding a complex subject;

* A graphical language for communicating that understanding;

* A set of management and human-factor considerations for guiding and controlling the use of the methodology.

$\mathrm{IDEF}_{0}$ uses top-down decomposition to break-up complex topics into small pieces which can be more readily understood. The diagrams are related in a precise manner to form a coherent model of the subject.

The whole system and the relationship of any part to the whole remains visible. This means that the environment in which an activity takes place is shown in terms of the effects of other activities and externalities which impinge upon the activity in question.

The graphical language of $\mathrm{IDEF}_{0}$ uses boxes and arrows coupled together in a simple syntax as shown in Figure 1.

Each box on a diagram represents an activity. The arrows that connect to a box represent real objects or information

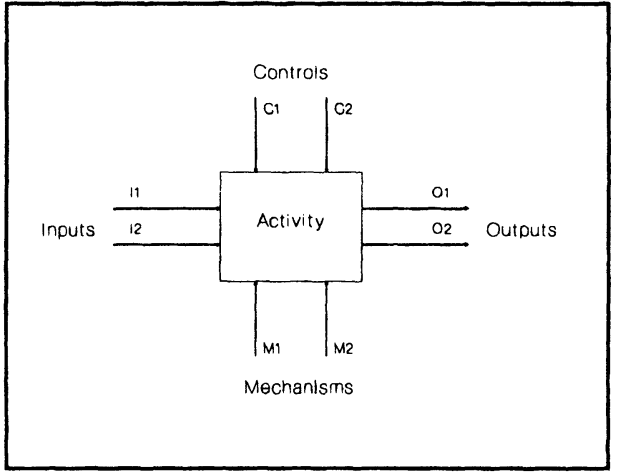

Fig. 1 IDEF $_{0}$ Syntax needed or produced by the activity. The side of the box at which an arrow enters or leaves shows the arrow's role as an input, a control or an output. Incoming arrows (which are shown on the left and top of the box) show the data needed to perform the activity. Outgoing arrows (right of the box) show the data created when the activity is performed. An input is converted by the activity into the output. A control describes the conditions or circumstances that govern the transformation. The bottom of the box is reserved to indicate the mechanisms or means (person, device, computer model etc.) used to carry out the activity.

$\mathrm{IDEF}_{0}$ is a method very well suited to the specification outlined earlier. Its specific strengths lie in that it is a tool designed for modelling processes and in our view it is relatively easy to use. It uses a structured set of guidelines based around hierarchical decomposition, with excellent guidance on abstraction at higher levels. If used well this ensures a good basis for communication and a systems perspective. 


\section{DESIGN OF NEW PROCESSES}

Once a model of a process has been created, a part of the process can be selected for redesign by benchmarking. The process model shows how the part must link in to the whole (in terms of the inputs, outputs and constraints) and provides a boundary within which activities can be redesigned. Thus the model provides the means to identify activities which can be replaced by better activities, the ideas for which may come from benchmarking.

Whilst research is continuing into the identification of standard business processes, it is clear that certain activities must be performed by most companies. This was tested in previous work [Childe 1991] in which an attempt was made to divide production management into its constituent tasks, and then to decompose these tasks into lower level elements, and so on as far as possible. For use in benchmarking, the model provides a structure in which the company can determine that a particular business activity is required, and use benchmarking to help to decide what lower level tasks should be used. This analysis can be applied at any level of abstraction, where the higher level always sets the requirement to be fulfilled by the lower level.

For each of the tasks in the model an attempt was made to determine why the task was required for the particular company. These task determinants aid the use of the model as a template to determine which tasks are required in a company under investigation.

Three types of task were recognised.

\section{Core tasks}

Some tasks appear to be necessary in every manufacturing company, in which case the benchmarking exercise could only affect the way in which the task was performed. These tasks were regarded as "core tasks". These included for example "Process orders", "Handle goods inward".

The decomposition of a core task could include optional tasks according to the way in which the core task was performed, particularly the decision whether or not to computerise the task. Thus the critical question for a core task is only how it should be done, which is determined by the selection of lower level tasks of which it is constituted.

\section{Optional tasks}

In the cases where the task requirement was seen to depend upon the situation, the task was regarded as "optional", since there would clearly be cases in which the task was not required. Examples of these include "Confirm order to customer", "Inspect goods". Where they could be determined, the particular reasons for optional tasks being necessary were recorded.

\section{Dependent tasks}

These were tasks which were found in the decomposition of optional tasks, but which were not themselves optional. These were necessary in any instance in which the parent task was required, thus depending upon the appearance or non-appearance of an optional task. For example, "Report capacity requirements" is an optional task whose decomposition must 
always include "Aggregate product profiles" and "Identify work for specific time buckets". These tasks are therefore compulsory in the case of the parent task being required.

The design of a new system, or the amendment of an existing system, depends upon being able to take important decisions about the way tasks should be carried out. Inevitably this means identifying the most appropriate set of lower level tasks to fulfil the task, and then for each of the tasks to select the means of carrying out the task, such as by human or mechanical/electronic means.

Work is proceeding on the development of generic process models which can reduce the time taken to produce the initial model for benchmarking. These models will also allow easier comparison between companies.

\section{CONCLUSION}

Effective benchmarking depends upon being able to identify correctly suitable activities in example companies, through analysis of the activity itself, its performance objectives and measures, and the competitive situation of the business. Good understanding of the role of any activity to the competitiveness of the business can be provided by an approach which sees the activity in the context of a business process. A modelling technique such as $\mathrm{IDEF}_{0}$ can be utilised to provide an understanding of the activities in question and to provide the basis for redesigning the process. Decomposition of the process into its constituent activities, tasks and sub-tasks provides the means to decide at what level the benchmarking activities should be conducted, thus identifying the correct unit of analysis.

\section{REFERENCES}

CAMP R, 1989, Benchmarking - The search for industry best practices that lead to superior performance, American Society for Quality Control

CHAMBERS, 1988, Chambers English Dictionary, W \& R Chambers Ltd and Cambridge University Press

CHILDE S J, 1991, The design and implementation of manufacturing infrastructures, $\mathrm{PhD}$ Thesis, Polytechnic South West

CIM-OSA Standards Committee, 1989, CIM-OSA Reference Architecture, AMICE ESPRIT

DAVENPORT T H \& SHORT J E, 1990, The new industrial engineering: information technology and business process redesign, Sloan Management Review, Summer

FINE C H \& HAX A C, 1984, Designing a manufacturing strategy, WP \# 1593-84, Sloan School of Management, MIT, USA

HAWKINS J M H, 1984, (Compiler), Oxford Paperback Dictionary, Oxford University Press 
HAYES R H \& PISANO G P, 1994, Beyond world-class: the new manufacturing strategy, Harvard Business Review, Jan-Feb

HICKMAN L J, 1993, Technology and Business Process Re-engineering: Identifying Opportunities for Competitive Advantage, British Computer Society CASE Seminar on Business Process Engineering, London, 29 June

RALSTON D, 1992, Measure for measure, Proc. 27th Annual Conference of British Production and Inventory Control Society, (BPICS), November, pp225-237

SMITH S, WHITTLE S, TRANFIELD D \& FOSTER M, 1992, Implementing Total Quality the downside of best practice, in Hollier R H, Boaden R J and New S J (Eds.) International Operations: Crossing Borders in Manufacturing and Service, Elsevier 